Www.jmscr.igmpublication.org

Impact Factor (SJIF): 6.379

Index Copernicus Value: 79.54

ISSN (e)-2347-176x ISSN (p) 2455-0450

crossrefDOI: https://dx.doi.org/10.18535/jmscr/v6i10.134

Journal Of Medical Science And Clinical Research

IGM Publication

An official Publication of IGM Publication

\title{
Ferric reducing capacity and Antioxidant activity of Ayabirungaraja $\operatorname{karpam}(\mathrm{ABK})$
}

Authors

\author{
Varnakulendren $\mathbf{N}^{1}$, V. Elango ${ }^{2}$
}

${ }^{1} \mathrm{PhD}$ Research scholar, Department of Siddhamedicine, Tamil University, Thanjavur

${ }^{2}$ Professor and HOD, Department of Siddhamedicine, Tamil University, Thanjavur

\begin{abstract}
$A B K$ is the metallic based herbal medicine, no scientific testimonial exist to conform its action and potential efficacy to proof the ancient siddhars' quotation about Ayabirunkaraja katpam which is mentioned in reputed siddha text siddha vaithiya thirattu" whereas quoted it is best remedy for Anemia, grey hair and Weakness.

Powdered samples $(10 \mathrm{~g})$ were extracted with $100 \mathrm{ml}$ of solvents (hexane, ethyl acetate, methanol, ethanol and water) and kept for $3 \mathrm{~h}$ at room temperature. For antioxidant activity, the solvent was evaporated using a rotovapor (Make: Buchi, Model: $R$-300) and dry extract was obtained. The extract was then redissolved in water at $100 \mathrm{mg} / \mathrm{ml}$ ratio and used for the analysis. RBC membrane stabilization potential of plant extracts were investigated according to the methods proposed by Sakat et al. (2010). Human blood (2 $\mathrm{ml}$ ) was drawn from volunteer in a heparinised tube and centrifuged at $2000 \mathrm{rpm}$ for $10 \mathrm{~min}$. The pellet (RBC cells) was washed twice with PBS $(9 \mathrm{ml})$ and finally the pellet was re-suspended in $10 \mathrm{ml}$ of PBS. The extract $(500 \mu \mathrm{l})$ were added to $1 \mathrm{PBS}, 1 \mathrm{ml}$ of $3 \% \mathrm{H}_{2} \mathrm{O}_{2}$ and incubated for $30 \mathrm{~min}$. Based on the absorbance, the percentage of RBC membrane damage and inhibition of membrane damage were calculated.

It is concluded that the aqueous extract of Auabirungaraja karpam showed appreciable antioxidant and ferric reducing capacities and effective in preventing $R B C$ membrane damage which due to oxidative stress.
\end{abstract}

Keywords: RBC, Antioxidant, Membrane.

\section{Introduction}

ABK is used by Traditional practioners in Sri Lanka and commonly used in government sector and Private Practioners in India. The ABK is included in the essential drug list of siddha medicine by department of AYUSH drug control cell since 2013. The researchers reported that all kayakalpa plants have anti-radical and scavenging activity. The mechanism of antioxidant activity is describes as, prevention of free radical chain initiation, binding of transition metal iron catalysts, decompositions of peroxides. Prevention of continued hydrogen abstraction, reductive capacity and radical scavenging (Diplock et al, 1997). The reducing properties are generally associated with the presence of reductones (Duh,1998),thus exert antioxidant actions by breaking the antioxidant action by breaking the 
free radical chain and by donating the hydrogen atom and also reductones reputed to react with certain precursors of peroxide, thus preventing peroxide formation.(Gordon,1990).

Free radical is molecule or molecular fragment that contains one or more unpaired electron in its outermost orbital, highly reactive and imbalance molecules which are by product of normal metabolism and associated with degenerative and destructive process of healthy cells. Free radicals steal electron from healthy cells to neutralize their own charge causing cellular damage because they are like robbers which are deficient in energy. The modern lifestyle, fast foods, obesity and physical inactivity are the major risk factor for production of free radicals and reactive oxygen spp. The generation of free radicals beyond the scavenging ability of antioxidant defences result in Macro and micro vascular dysfunction. Oxidative stress is the prime reason for molecular pathogenesis which result from an imbalance between radical generation and radical scavenging system. The harmful elements are super oxide anions radicals, hydroxyl radicals and hydrogen peroxide .Damaging essential biomolecules such as protein, DNA and lipids which eventually causes inflammation, Kidney diseases, diabetic mellitus, graying, ageing and several degenerative diseases in humans, (Halliwell, 1997). The phenolic acids, Polyphenol, flavinoids inhibit the oxidative stress mechanism and thus prevent damage of cells.

RBC used as model cell by a several researchers to the study of interaction of drugs with membrane. It also has been reported that the production free radicals such as lipid peroxide and superoxide in various condition like heat induced stress haemolysis due to cell membrane de stabilization. (Agarwal and Rangari,2003). The therapist search natural antioxidants since they are free from health hazards. The Ayabirungaraja karpam contain iron compounds and two herbs which are being used in the processing of drug formulation have sound antioxidant activity reported from recent research records.
Therefore the aim and objective of the present study was to determine the phenolic content and to establish the capacity of ferric reducing power, characterize the antioxidant and RBC membrane stabilization assay of the different extract of Ayabirunkaraja karpam.

\section{Methodology}

Sample collection: The samples (ABK formulation) were collected from the customer in powdered form by CARISM office (SR No. 1703-X-2595 dt. 16-03-2017).

Preparation of extract: Powdered sample $(10 \mathrm{~g})$ was extracted with $100 \mathrm{ml}$ of solvents (hexane, ethyla acetate, methanol, ethanol and water) and kept for $3 \mathrm{~h}$ at room temperature. The extracts were then separated using Whatman No. 1 filter paper and used for further experiments. For antioxidant activity, the solvents were evaporated using a rotovapor (Make: Buchi, Model: R-300) and dry extract was obtained. The extract was then re-dissolved in water at $100 \mathrm{mg} / \mathrm{mL}$ ratio and used for the analysis.

Total phenol content: The total phenolic content of extract was estimated according to the method of Singleton et al. (1999). Suitably diluted sample $(100 \mu \mathrm{l})$ was taken with $250 \mu \mathrm{l}$ of Folin'sCiocalteu reagent and $1000 \mu \mathrm{l}$ of $5 \%$ of $\mathrm{Na} 2 \mathrm{CO} 3$ was added and incubated for $30 \mathrm{~min}$ in dark. Then the absorbance was measured at $720 \mathrm{~nm}$ using Spectrophotometer. A calibration curve was prepared using standard gallic acid (16 - 100 $\mathrm{mg} / \mathrm{L} ; \mathrm{y}=0.0094 \mathrm{x}-0.0585 ; \mathrm{R} 2=0.9939)$ and used to calculate the total phenolic content of the extract and the results were expressed as gallic acid equivalents (mg GAE / $100 \mathrm{~g}$ sample).

Ferric reducing power: The reducing power of extract was determined according to the method of Oyaizu (1986). Samples (2.5 ml) in phosphate buffer $(2.5 \mathrm{ml}, 0.2 \mathrm{M}, \mathrm{pH} 6.6)$ were added to potassium ferricyanide $(2.5 \mathrm{ml}, 1.0 \%)$ and the mixture was incubated at $50^{\circ} \mathrm{C}$ for $20 \mathrm{~min}$. 
Trichloroacetic acid $(2.5 \mathrm{ml}, 10 \%)$ was added, and the mixture was centrifuged at $650 \mathrm{x} \mathrm{g}$ for $10 \mathrm{~min}$. The supernatant $(5.0 \mathrm{ml})$ was mixed with ferric chloride $(5.0 \mathrm{ml}, 0.1 \%)$, and then the absorbance was read spectrophotometrically at $700 \mathrm{~nm}$. Based on the absorbency value, the ferric reducing power of extract was expressed.

Antioxidant activity: The DPPH radical scavenging assay was used to analyze the antioxidant property of aqueous extract of the sample by following Sanchez-Moreno et al. (1998) method. The extract $(100 \mu \mathrm{l})$ was added to $0.9 \mathrm{ml}$ of methanolic solution of DPPH (2.5 $\mathrm{mg} / 100 \mathrm{ml}$ ) and the reactants were incubated at room temperature for $30 \mathrm{~min}$ in dark. Different concentrations of Butylated hydroxyanisol (BHA) were used as a standard and the solvent (distilled water) was used instead of extract in control. After $30 \mathrm{~min}$, the absorbance was measured at $515 \mathrm{~nm}$ using a spectrophotometer and the radical scavenging activity of the extract was calculated and expressed on percentage basis.

\section{Membrane stabilization potential: $\mathrm{RBC}$} membrane stabilization potential of plant extracts were investigated according to the methods proposed by Sakat et al. (2010). Human blood (2 $\mathrm{ml}$ ) was drawn from volunteer in a heparinised tube and centrifuged at $2000 \mathrm{rpm}$ for $10 \mathrm{~min}$. The pellet (RBC cells) was washed twice with PBS (9 $\mathrm{ml}$ ) and finally the pellet was re-suspended in 10 $\mathrm{ml}$ of PBS. The extract (500 $\mu \mathrm{l})$ were added to 1 PBS, $1 \mathrm{ml}$ of $3 \% \mathrm{H} 2 \mathrm{O} 2$ and incubated for $30 \mathrm{~min}$. In normal control, $1 \mathrm{ml}$ PBS was added instead of extract and in standard group, $1 \mathrm{ml}$ of ascorbic acid was added instead of extract and in negative control only $\mathrm{H} 2 \mathrm{O} 2$ was added. After incubation, the contents were centrifuged at $2000 \mathrm{rpm}$ for 10 min and the supernatant was used to measure the absorbance at $520 \mathrm{~nm}$. Based on the absorbance, the percentage of RBC membrane damage and inhibition of membrane damage were calculated.
Extract yield: The extract yield juice of lemon and Wedelia chinensis was determined based on Joshi and Aeri (2009) method. Fresh lemon fruits (4 Nos.) were used to prepare the juice by hand squeezing and the $W$. chinensis plant juice was prepared by taking $25 \mathrm{~g}$ of fresh material with 50 $\mathrm{ml}$ of distilled water and crushed in a domestic mixer grinder for $5 \mathrm{~min}$. Then the contents were filtered in a filter paper and $10 \mathrm{ml}$ volume was transferred to pre-weighed beakers and kept at $105^{\circ} \mathrm{C}$ for $3 \mathrm{~h}$ in a oven. After cooling to room temperature in a desiccator, the gross weight was recorded and based on difference in weight, the extract yield was calculated and expressed on percentage basis.

\section{Results and discussion \\ Total phenolic content}

Aqueous extract of $\mathrm{ABK}$ formulation was noted to contain higher amount of total phenolic compounds (237 mg GAE / 100 g) when compared to other solvent extracts (Figure 1). Since it is a metal based preparation and the percentage of herbal ingredients are very less, the polyphenolic content was low. The polyphenols present in $\mathrm{ABK}$ formulation might be high polar in nature and thus extracted only with water.

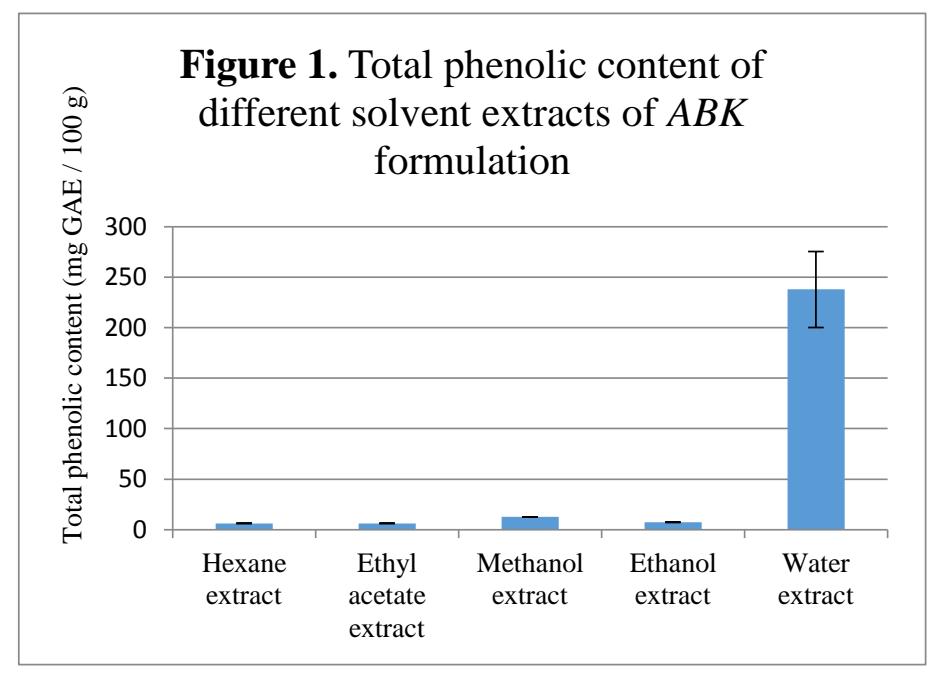

\section{Ferric reducing power}

Ferric reducing power of fresh juices of lemon, Eclipta alba and Wedelia chinensis was analyzing and the results are shown in Figure 3. In this assay, Fe (III) is reduced to Fe (II) by the 
antioxidant compound through electron transfer. The reduced Fe (II) forms the Pearl's blue complex, which can be measured at $700 \mathrm{~nm}$. Between the samples analyzed, W. chinensis juice exhibited higher ferric reducing power $(77.54 \%)$ when compared to Eclipta alba (53.38\%) lemon juice (38.16\%). The ferric reducing power of Wedelia chinensis juice was found to be higher when compared to Eclipta alba juice and this might be the reason why the Wedelia chinensis was used to prepare ABK formulation. Since, both lemon and Wedelia chinensis juices have remarkable ferric reducing power, the phytochemicals particularly the polyphenols of these plants were utilized for the conversion of ferric form of iron to ferrous form and hence, the final formulation of $\mathrm{ABK}$ revealed poor antioxidant power. Conversion of $\mathrm{Fe}$ (III) in to $\mathrm{Fe}$ (II) form is of great biological significance, because the ferrous form (Fe II) is the only bioavailable form and hence, the iron must be converted into ferrous form from ferric state before drug administration and in this line, the use of these two plant extracts during the preparation of $\mathrm{ABK}$ formulation are more useful.
Figure 3. Ferric reducing power of juices of lemon, Wedelia chinensis and Eclipta alba

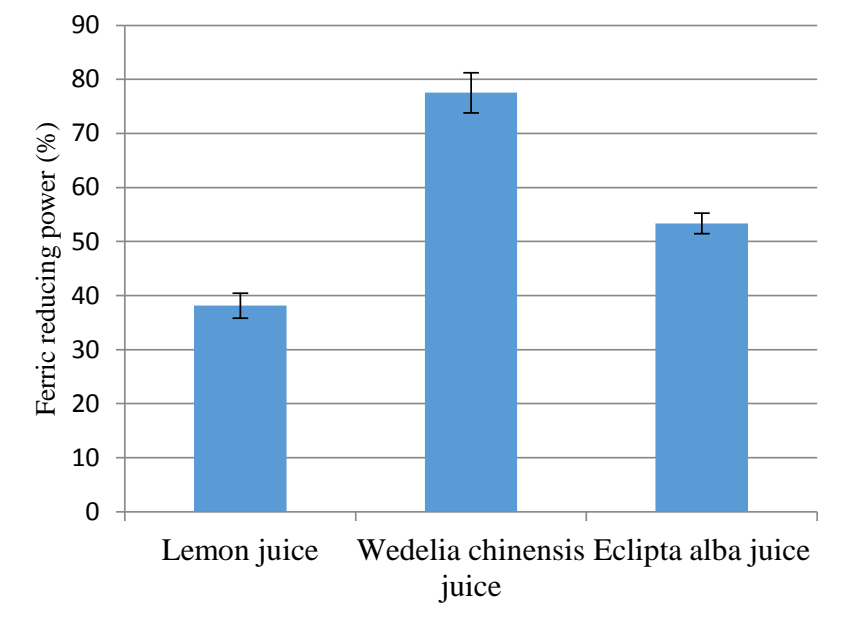

\section{Antioxidant activity}

Aqueous extract of $\mathrm{ABK}$ formulation exhibited moderate antioxidant activity $(42.68 \%)$ at a concentration of $100 \mathrm{mg} / \mathrm{ml}$ (Figure 2). The IC-50 value of $119 \mathrm{mg} / \mathrm{ml}$ indicated that the $\mathrm{ABK}$ formulation has moderate antioxidant power when compared to the standard gallic acid (IC-50 $=2.34$ $\mathrm{mg} / \mathrm{ml}$ ). Since the herbal phyto-constituents from lemon and Wedelia chinensis juices might have been used to reduce the iron (III) into iron (II) during the preparation of $\mathrm{ABK}$ formulation, the final drug showed moderate antioxidant power.

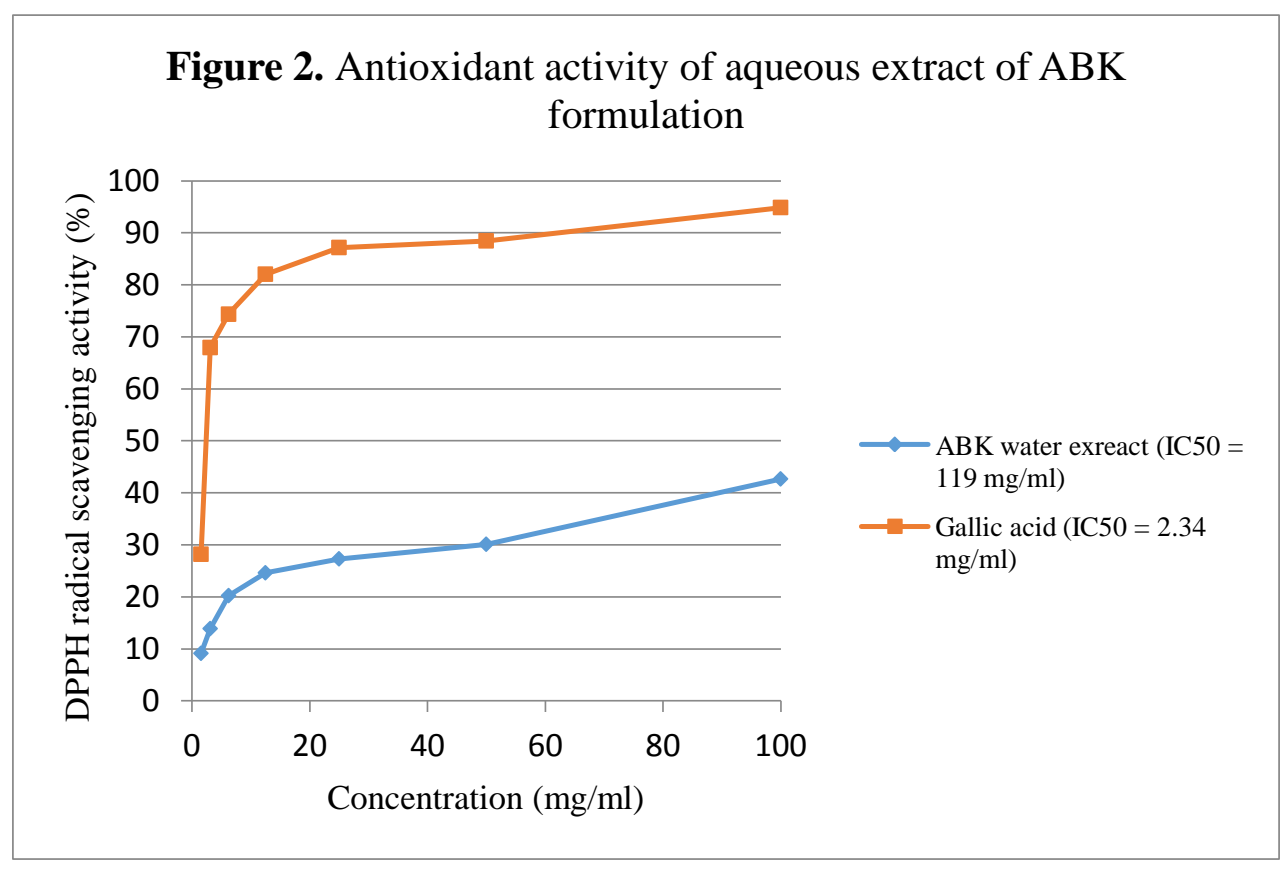




\section{Extract yield}

The extract yields of juices of lemon and $W$. chinensis were determined and the results are expressed on dry weight basis in the Figure 4. Between the two samples, lemon juice demonstrated higher level of dry weight $(42.50 \mathrm{~g} /$ L) when compared to W. chinensis (13.25 g / L). Since, huge volume of lemon and $W$. chinensis juices are used during the preparation of $\mathrm{ABK}$ formulation, they also might add the final dry weight of the drug. But, the constituents of these juices have either been used to convert the iron from ferric to ferrous form or may be denatured due to heat treatment (sooriya pudam) during the preparation of $\mathrm{ABK}$ formulation.

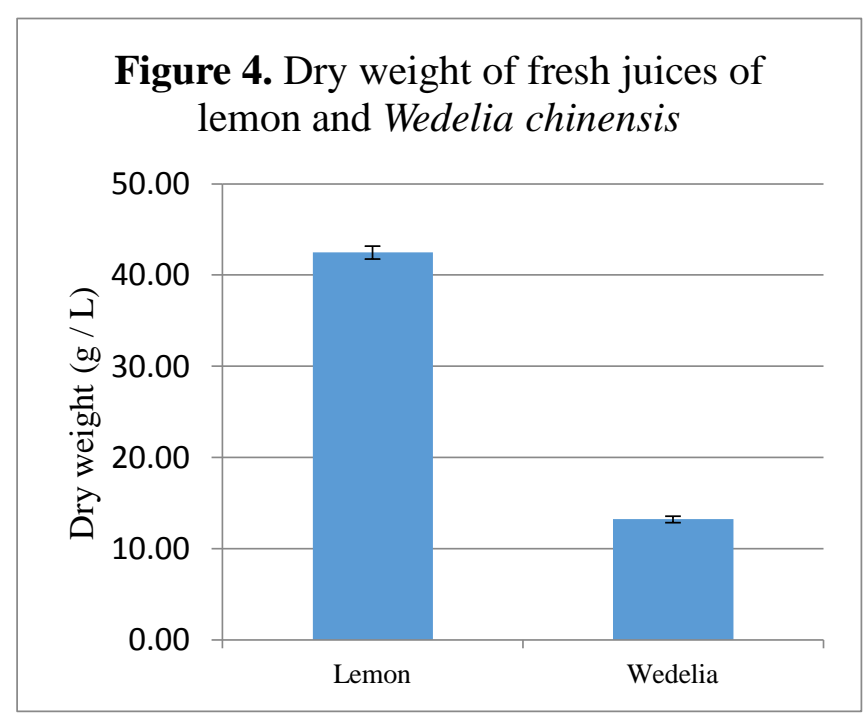

\section{Membrane stabilization potential}

Aqueous extract of $\mathrm{ABK}$ formulation is found to be effective to inhibit the $\mathrm{H} 2 \mathrm{O} 2$-induced oxidative damage in RBC membrane $(67.65 \%)$ when compared to reference standard vitamin-C (41.67\%) (Figure 5). Since the water soluble components of $\mathrm{ABK}$ formulation has remarkable level of RBC membrane stabilization potential, it could prevent oxidative-stress induced haemolysis and thus helpful in preventing the anaemia.
Figure 5. RBC membrane stabalization potential of $\mathrm{ABK}$ formulation

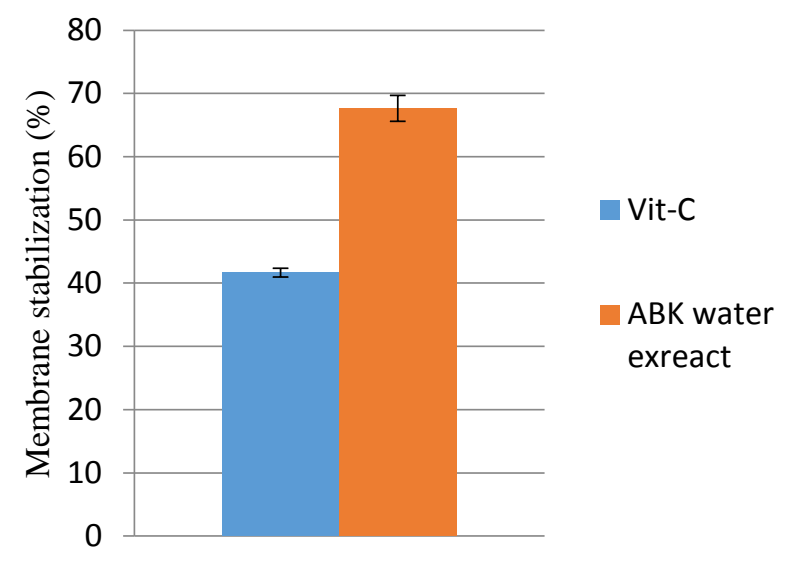

\section{Conclusion}

The plant Eclipta alba and Wedelia chinensis are commonly called as Birunkarajam therefore the drug manufacturers used either one of this plant but this research study revealed that W.chinesis found to be higher ferric reducing power compare to E.alba, hence the use of W.chinensis extract is more useful in the preparation of ABK.The total phenolic content as well as antioxidant activity were found to be moderate in $\mathrm{ABK}$ formulation, due to the fact that the herbal components were already used to convert the ferric form of iron to ferrous form during preparation. The herbal ingredients like lemon and Wedelia chinensis juices were incorporated in $\mathrm{ABK}$ preparation and their phytochemicals are either denatured during natural heating process or might be used to reduce the iron to ferrous form. However, the aqueous extract of $\mathrm{ABK}$ formulation showed appreciable RBC membrane stabilization effect, which could be one of the mechanisms for its anti-anaemic action.

\section{Bibliography}

1. Siddharth Shrivasta, Rakesh. K, Sindhu, Sanjeeve kumar,Pradeeep kumar.(2009). Studies on Antipsoriatic and phytochemical evaluation of Thespesia populnea; IJ. Pharmacy and Pharmaceutical sciences, Vol 1,Nov-Dec. 
2. Vasudevan M,Kumar Kishore Gunnam, Parle M,(2017) Antinoceptive and anti inflammatory effect of Thespesia populnea bark extract.J.Ethno Pharmcol;109:264270 .

3. Inbaraj, J,J., Gandhidasan., Murukesan, R.,(1999); Cytotoxicity and Superoxide anion generation by some naturally occurring quinines, FrRad Biomed ;26:1072-78.

4. Parle, M., Vasudevan, M.,(2006) Pharmacological action of Thespesia populnea relevant to Alzemiers disease, Phytomed;;13:p677-687

5. Chatterjee, A., Satyeshchandra,P.,(1992), The teratise of Indian medicinal plants, $5^{\text {th }}$ ed, Newdelhi: National Institute of communication;p 189-190.

6. Kiritikar, K.R, Basu,B.D.,(1994), Indian Medicinal Plants, $3^{\text {rd }}$ ed, Deharadun: Int.Book distributors, Book selles and and publishers;p340-342

7. Sanchez-Moreno, C., Larrauri, J.A. and Saura-Calixto, F.A. (1998). A procedure to measure the antiradical efficiency of polyphenols. Journal of the Science of Food and Agriculture, 76, 270-276.

8. Oyaizu, M. (1986). Studies on products of browning reactions: Antioxidant activities of products of browning reaction prepared from glucosamine. Japanese Journal of Nutrition, 44, 307-315.

9. Singleton, V.L., Orthofer, R., \& LamuelaRaventos, R.M. (1998). Analysis of total phenols and other oxidation substrates and antioxidants by means of Folin-Ciocalteu reagent. Methods in Enzymology, 299, 152-178.

10. Joshi, S., Aeri, V. 2009. Practical Pharmacognosy. 1st ed. New Delhi: Frank Bros \& Co., (Publishers) Ltd., pp. 290-293.

11. Sailahi,2012. Anticancer and health protection properties of citrus fruit components, Asia pacific journal of chemical nutrition, 11
12. Halliwell, B.,(1994); Antioxidant and human disease, curiosity,cause or consequences., Lancet, 344.

13. Manjamali, A, Berlin Grace V.M; Anioxidant activity of essential oil from Wedelia chinensis (Osbeck), Invitro and Invivo lung cancer bearing C57BC16 Mice.

14. Jeyaweera, D.M.A; (2005), Medicinal plants used in Ceylon Vol $11 \& 1 \mathrm{~V}, 2^{\text {nd }}$ ed, National science foundation, Srilanka

15. Shafag Noori,(2012); An Over view of Oxidative stress and Antioxidant defense system,Open Access,Scientific report,1(8)

16. Oxedapa,O.O, Famureva, A .J (1995); Antiprotease and membrane stabalization activities of extract of Fagera zanthoxylloids, Olax subscorpioides and Tetrapleura tetraptera; Int. J. Pharmacognosy; 33: 65-69.

17. Sessa,G, Weisman, G.,(1968); Effect of compound of the polyene antibiotic, Fillipin on Phospholipids spherules (liposome) and erythrocyte J. Biol. Che; 243:4363-4371.

18. Litmen, G.W, Litmen,R.J, Hendry,C.J (1979); Analysis of lipophilic carcinogenmembrane interection using human erythrocyte membrane system model. Cancer Res;243:4363-4371.

19. Horie, T., Sugiyane, V., Hanano, M.,(1976); The correlation between drug binding to human erythrocyte and its haemolytic action. J. Pharmacology,4: 116-122.

20. Neelkantan, S., Rajagopalan, V., Raman, P,V., Thespesone and Thespone, two new mansonones of heart wood of Thespesia populnea. Sol.ex Corr; Idian journal of chemistry, 1983;22B:95-96

21. Chaika, L,A., Khadzhai,(1977); Membrane stabalizing effect of medicinal substances used for the treatment of chronic venous insufficiency. Farmcol Toksikol,40: 306309. 
22. Kumar,G,S., Jeyaveera, K,N.,Kumar Ashok, C,K., Bharathi,T Sanjay, P., Umachigi, Samy Vrushabendr a(2008); Evalution of antioxidant properties of terpinoidal fraction of Hemedesmus indicus; The internet journal of Aesthetic and Antiageing medicine, 1:1-8.

23. Repetto,M,G., Lieusy (2002); Antioxidant properties of natural compound used in popular medicine for gastric ulcers.Brazil.J.Med.Biol.Res.,35:523-532.

24. Smith,C., Hallwell, B., Aruoama, O,T., (1992); Protection of albumin against the prooxidant actions of Phenolic dietary components. Food Chem.Toxicol;30:483489.

25. Agarwal, B,A., Rangari,V,D., (2003); Anti inflammatory and Antiarthiritc ativities of Lupeol and 19OH Lupeol isolated from Strobillanthus callosus and Strobillanthusvoicephoda roots. Indian. J. Pharmacol;35:384-387.

26. Srivastava, S,N., Bhakuni,D,S., Sharma, V,N., Chemical investigation of $T$. populnea soland; Short communication, 1963:451.

27. Neelkantan, S., Rajagopalan, V.,Raman, $\mathrm{P}, \mathrm{V}$., Thespesone, Thespone, Two new mansonones of heart wood of T.Populnea sol. ex.corr; Indian journal of chemistry,1983;22B: 95-96.

28. Harbone J,B.,(); Phytochemical methodsguide to modern technique of plant analysis, $2^{\text {nd }}$ ed, India, Chapma and Hall, pp653. Sanchez- Moreno, C., Larrauri, J.A. and Saura-Calixto, F.A. 1998. A procedure to measure the antiradical efficiency of polyphenols. Journal of the Science of Food and Agriculture, 76, 270276. 